\title{
Object-based image analysis for the assessment of mineral extraction in conflict regions - a case study in the Democratic Republic of the Congo
}

\author{
Olaf Kranz $^{\mathrm{a}, \mathrm{b}}$, Elisabeth Schoepfer ${ }^{\mathrm{c}}$, Kristin Spröhnlec ${ }^{\mathrm{c}}$, Stefan Lang ${ }^{\mathrm{a}}$ \\ ${ }^{\text {a }}$ Department of Geoinformatics - Z_GIS, University of Salzburg, Salzburg, Austria - olaf.kranz@stud.sbg.ac.at, \\ stefan.lang@sbg.ac.at) \\ ${ }^{\mathrm{b}}$ Research Section, Helmholtz Association of German Research Centres, Head Office, Berlin, Germany - olaf.kranz@helmholtz.de \\ ${ }^{c}$ German Aerospace Center (DLR), German Remote Sensing Data Center (DFD), Oberpfaffenhofen, Germany - \\ elisabeth.schoepfer@dlr.de, kristin.sproehnle@dlr.de
}

KEY WORDS: land cover change; natural resources; mining; object-based image analysis; remote sensing

\begin{abstract}
:
In this study object-based image analysis (OBIA) techniques were applied to assess land cover changes related to mineral extraction in a conflict-affected area of the eastern Democratic Republic of the Congo (DRC) over a period of five years based on very high resolution (VHR) satellite data of different sensors. Object-based approaches explicitly consider spatio-temporal aspects which allow extracting important information to document mining activities. The use of remote sensing data as an independent, up-to-date and reliable data source provided hints on the general development of the mining sector in relation to socio-economic and political decisions. While in early 2010, the situation was still characterised by an intensification of mineral extraction, a mining ban between autumn 2010 and spring 2011 marked the starting point for a continuous decrease of mining activities. The latter can be substantiated through a decrease in the extend of the mining area as well as of the number of dwellings in the nearby settlement. A following demilitarisation and the mentioned need for accountability with respect to the origin of certain minerals led to organised, more industrialized exploitation. This development is likewise visible on satellite imagery as typical clearings within forested areas. The results of the continuous monitoring in turn facilitate non-governmental organisations (NGOs) to further foster the mentioned establishment of responsible supply chains by the mining industry throughout the entire period of investigation.
\end{abstract}

\section{INTRODUCTION}

The Democratic Republic of the Congo (DRC) is one of the most mineral-rich countries in the world. Several studies demonstrated that exploitation and trade of these resources contributed to fuel the conflict during the past decades (Le Billon 2010, 2005; Burnley 2011; Global Witness 2009; Mildner et al. 2011; Melvin and de Koning 2011). On the contrary, natural resources may contribute to peacebuilding through economic development and the generation of employment (Frerks et al. 2014; UNEP 2009). Mining in the DRC already started in the beginning of the $20^{\text {th }}$ century. Since a few years the mining sector was to a high extent militarised and is still characterised by informal artisanal and small-scale mining (ASM). During the past years increasing international pressure led to several initiatives towards certification, transparency and due diligence in order to implement traceable supply chains. Since 2010 exploitation sites in North and South Kivu have been integrated into one of these initiatives, the socalled ITRI Tin Supply Chain Initiative (iTSCI). The overall aim is to provide conflict-free minerals to international buyers. One of the largest cassiterite mines is Bisie which is located in the Walikale Territory in North Kivu. Bisie is not covered by iTSCI since this site is currently industrially exploited by Alphamin Resources Corporation, through its wholly owned subsidiary, Alphamin Bisie Mining SA (Witley and Leighton 2015, Witley et al. 2016). The planned underground exploitation and the expected start of production in 2018 can be seen as an important turning point through new economic opportunities for the entire region (ITRI 2015).

In order to provide a more detailed assessment of the dynamics of mining-related activities at the remote mining site of Bisie, socio-economic and political facts can be complemented by information gathered from satellite-based monitoring. Objectbased change detection (OBCD) with very high resolution (VHR) satellite data provides a powerful methodological framework for such in-depth assessments. In the presented study data from different satellite sensors have been used covering a period of five years between 2010 and 2015 .

\section{STUDY AREA AND DATA}

The area of investigation is located in the Walikale territory in the North Kivu province of the DRC $\left(1^{\circ} 2^{\prime}\right.$ S $27^{\circ} 44^{\prime}$ E; Fig. 1).

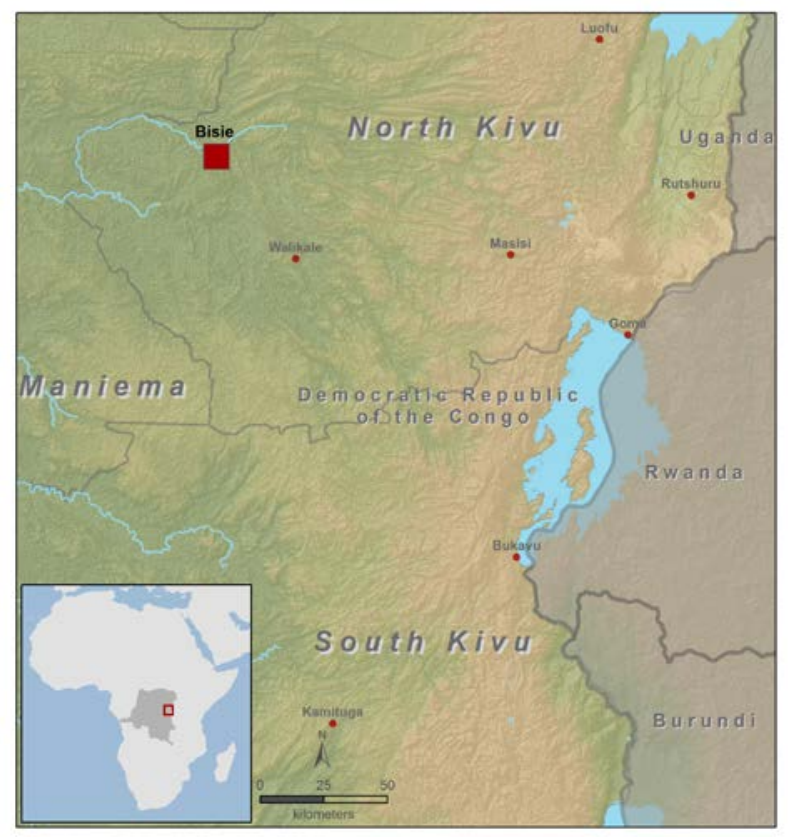

Fig. 1. The study site Bisie in North Kivu, DRC.

Bisie is one of the most well-known mining areas with more than 3,000 miners working at the site at the peak of exploitation 
in autumn 2010 (Zingg Wimmer and Hilgert 2011). The mining site can only be reached by foot. The main trading centres Mubi and Ndjingala are in a distance up to $30 \mathrm{~km}$. From these villages minerals - mainly cassiterite - are transported to Goma by cargo plane (Zingg Wimmer and Hilgert 2011). The province capital is the major export point for Bisie's cassiterite.

For the monitoring five VHR satellite images for the period of April 2010 until March 2015 have been acquired (Table 1).

Table 1. Data acquisition for VHR satellite data. ${ }^{1}$

\begin{tabular}{ccc}
$\begin{array}{c}\text { Sensor } \\
\text { type }\end{array}$ & $\begin{array}{c}\text { Acquisition } \\
\text { time }\end{array}$ & $\begin{array}{c}\text { Spatial } \\
\text { resolution (m) }\end{array}$ \\
\hline GeoEye-1 & $02 / 04 / 2010$ & 0.5 \\
\hline GeoEye-1 & $08 / 09 / 2010$ & 0.5 \\
\hline IKONOS & $10 / 03 / 2011$ & 1 \\
\hline WorldView-2 & $11 / 06 / 2014$ & 0.5 \\
\hline WorldView-3 & $15 / 03 / 2015$ & 0.4
\end{tabular}

${ }^{1}$ GeoEye-1 \& IKONOS: (CGeoEye, Inc. (2010, 2011), provided by eGEOS S.p.A. under GSC-DA. WorldView-2/-3: CDigitalGlobe, Inc. (2014, 2015), provided by European Space Imaging GmbH.

\section{METHODOLOGY}

The detection of small-scale changes related to artisanal mining activities requires the availability and combination of panchromatic (highest spatial resolution) and multispectral (spectral information) bands. The overall workflow is shown in Fig. 2. Image pre-processing started with layer stacking of the spectral bands followed by the pan-sharpening of the imagery. Several tests have been applied in order to select the best pansharpening technique. We utilized two different algorithms depending on the sensor type. For GeoEye and IKONOS imagery the Hyperspherical Color Sharpening (HCS) was used while the WorldView data has been processed with the University of New Brunswick (UNB) algorithm (Christopher and Deskevich 2014; Zhang and Mishra 2014; Ghosh and Joshi 2013; Tu et al. 2012). Further pre-processing steps included orthorectification, resampling and co-registration of the imagery. Based on these pre-processed images a multiresolution image segmentation was applied as implemented in the software package eCognition (Trimble Geospatial Imaging). This segmentation results in hierarchically structured objects (Hussain et al. 2013; Blaschke 2010; Johansen et al. 2010; Lang 2008; Im et al. 2008; Benz et al. 2004; Lang and Blaschke 2003) which were classified into five classes based on their spectral properties, size, shape, texture and topological relations (Schöpfer et al. 2010; Blaschke 2010; Blaschke 2005; Benz et al. 2004). The classification accuracy could be improved by the integrated analyses of several band ratios, the Normalized Difference Vegetation Index (NDVI) and the panchromatic band. Thresholds applied to these additional information layers allow for an easy and rapid adjustment of the underlying ruleset according to the specific conditions of different satellite data. Thus the approach can be regarded as standardised and transferable and facilitates at the same time certain flexibility. The classification process starts with the separation of bare soil and vegetated areas (Fig. 2) initially based on the NDVI ensuring a good separation of areas with low (bare soil) and high (vegetation) values. Since the entire Walikale territory is predominated by dense primary forest we assume that bare soil objects indicate mining-related activities. Vegetated areas were further subdivided into primary forest and secondary forest to allow qualitative statements about the development of the vegetation surrounding the mining site. The fourth class comprises dwellings. Due to cloud coverage at the time of image acquisition, an additional class had to be introduced for the 2010 imagery depicting cloud covered areas. For the feature extraction spectral information along with band-ratio and spectral-derivative features were used to discriminate the different classes (Fig. 2).

Based on the classification for each time interval object-based change detection (OBCD) was applied incorporating objectoriented data modeling concepts described by Tiede (2014). A full (i.e. horizontal and vertical) topological data model is used as implemented in the software package eCognition (Trimble Geospatial Imaging) to consider relations of objects at different hierarchical scales (Tiede 2014). The process of change comparison is comparable to spatial overlay procedures within a GIS and results in a layer with objects indicating changes. Horizontal topological relations allow generalisation and cleanup procedures (e.g. eliminating sliver polygons). The OBCD was implemented by working with the 'maps' functionality in eCognition Version 8 (Definiens 2009). Two independent maps were generated to perform the land cover classification independently on two input data sets. Afterwards the maps were synchronized and the change detection applied based on a uniform object hierarchy in order to apply the class-related feature 'existence of sub-objects' for the identification of changes (Definiens 2009).

The generated classes were further aggregated to the final change classes: (no change), increased mining area, vegetation increase, vegetation decrease, new dwellings, and removed dwellings.

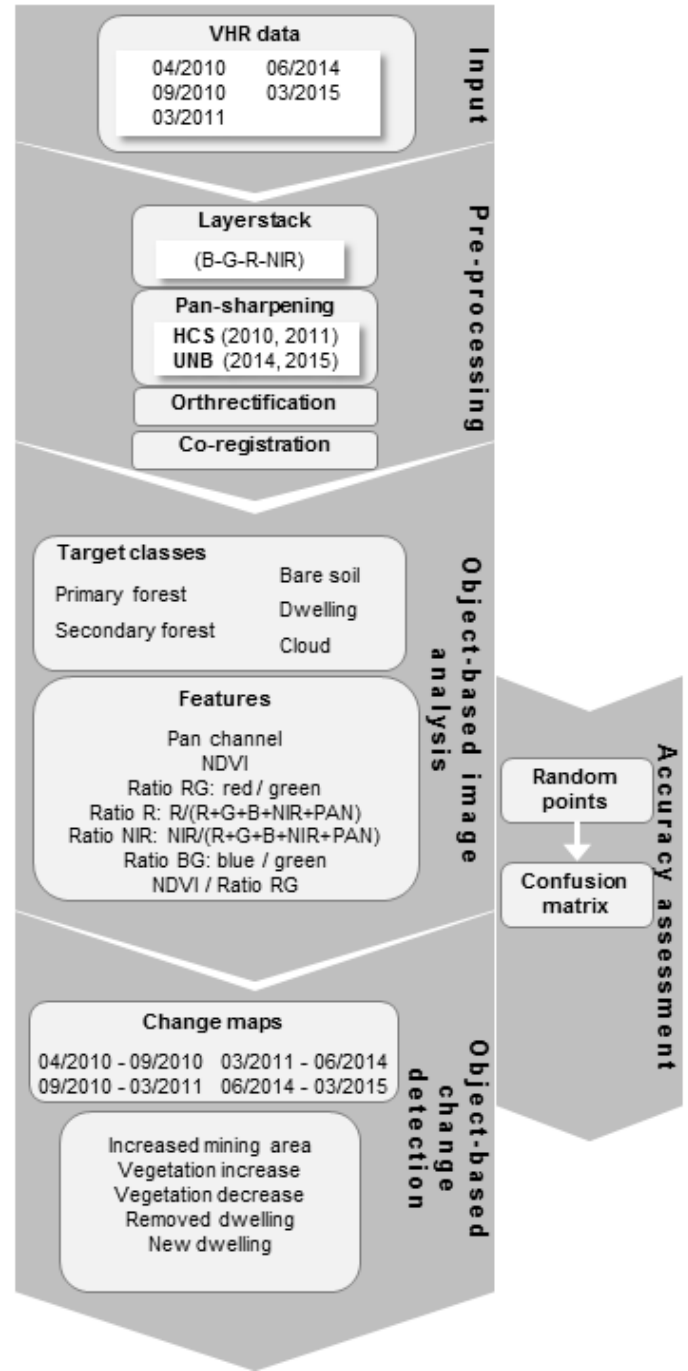

Fig. 2. Methodological workflow. 
4.

\section{RESULTS}

Based on the OBIA analyses, changes in land cover - in particular those related to mining activities - were monitored over the period from April 2010 until March 2015. Due to the small-scale of activities at Bisie it was essential to work on the full spatial and spectral resolution of the input images. At the extraction of minerals one cannot expect large-scale excavations but rather subtle changes indicating activities related to artisanal mining.

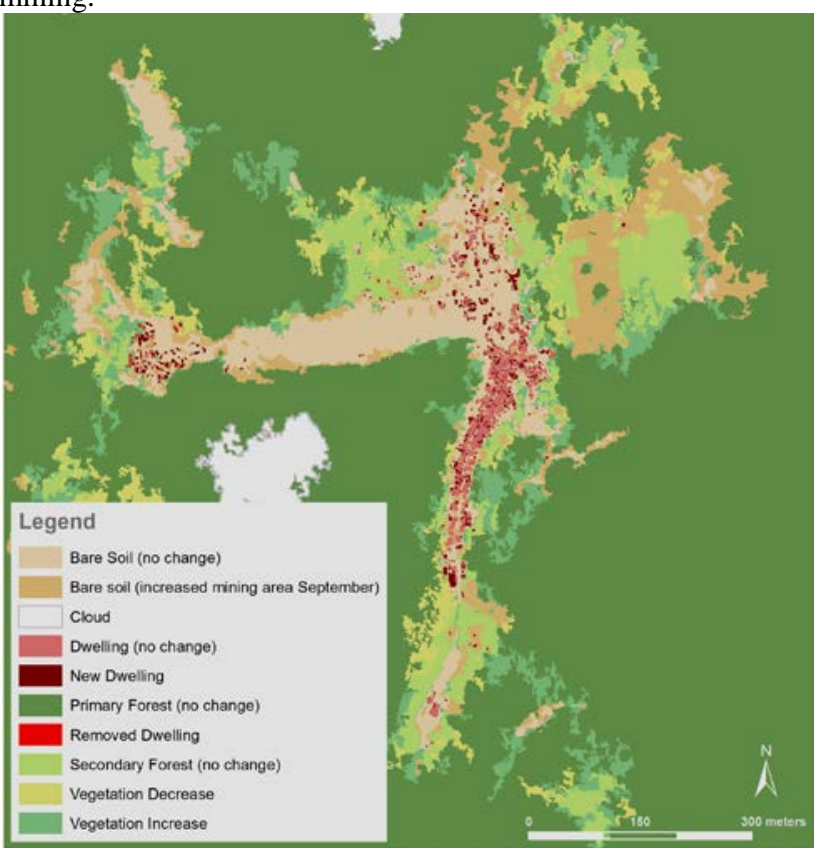

Fig. 3. Results of the land cover change from April 2010 to September 2010.

The most obvious indicator is the extension of the mining site itself as observed from April 2010 to September 2010 (Fig. 3) as well as further onwards until March 2011 (Fig. 4). Furthermore, this intensification of mineral extraction - also reported in studies of NGOs (Zingg Wimmer and Hilgert 2011) - is reflected by an increasing number of dwellings in 2010. Nevertheless, this number decreased significantly in the following months due to decreasing exploitation as result of a mining ban. Along with the reduction of minerals extraction not only the number of workers decreased but the area of bare soil declined as well underlining a minimization of mining activities. Nevertheless, in some places the mining area has been expanded suggesting that mining still continued at selected sites.

Consequently, the highest number of dwellings was reached in September 2010 also highlighting the peak of minerals extraction within the analyzed 5-years-period. During the same period new forest clearings became visible. An area east of the major mining site seems to serve as agricultural land and for the extraction of building timber. From 2011 until 2015 the terrain became successively overgrown (Fig. $5 \& 6$ ).

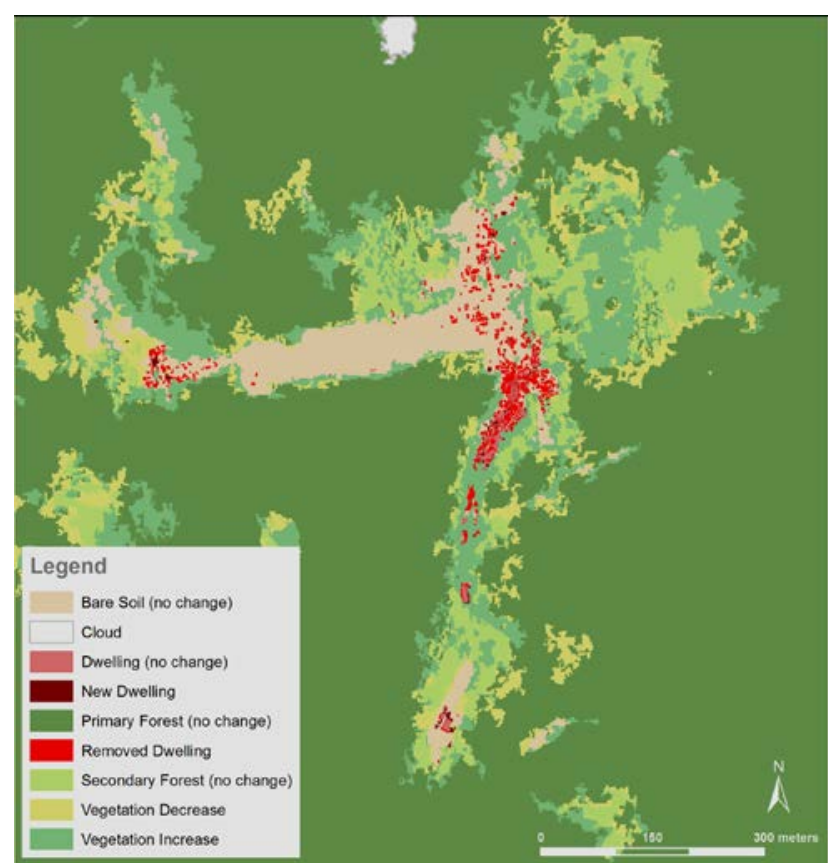

Fig. 4. Results of the land cover classifications from September 2010 until March 2011.

From September 2010 onwards a considerable shrinking of settlements was observed. In March 2015 almost all dwellings were removed except of some single ones in the central part of the mining site and larger facility buildings in the southern edge (Fig. 5 \& 6) that were even expanded. The time window between September 2010 and June 2014 has been used for visualisation here since both images have the same spatial resolution of $0.5 \mathrm{~m}$ which makes it easier to identify the mentioned subtle changes. Nevertheless, the same overall trend of reduced mining activity can be already observed until March 2011 utilising the IKONOS image.

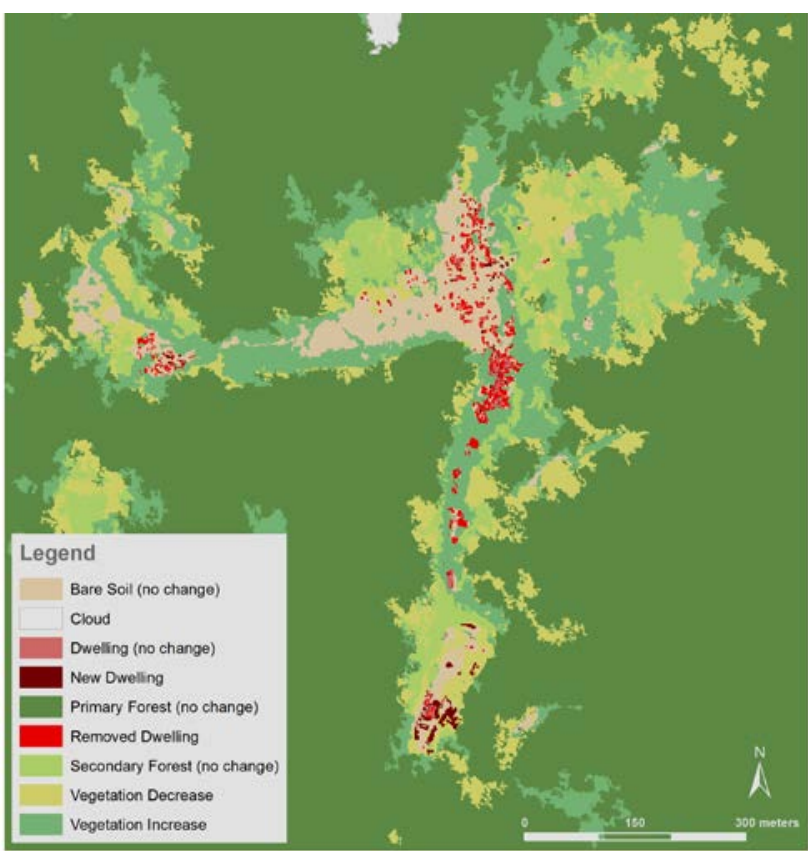

Fig. 5. Results of the land cover change from September 2010 to June 2014

Looking at the bare soil class over the 5-years-period a significant regrowth of vegetation becomes visible at the 
sidelines of those areas that were formerly digged in. Nevertheless, there is a remarkable turning-point in 2014 and further on in 2015: several clear-cuts east and north-east of the central mining area indicate professional exploration activities. Another indicator for this industrial development in Bisie is the construction of a road east of the mining site visible through a new linear area of bare soil (Fig. 6).

In summary, the monitoring over five years provided evidence for a considerable change in mining activities in Bisie. While 2010 represented a peak of artisanal mining activities a turningpoint became visible with characteristic land cover changes in the course of professional exploration in 2014/15. Furthermore, it could have been proved that despite a mining ban between autumn 2010 and spring 2011 minerals extraction still continued.

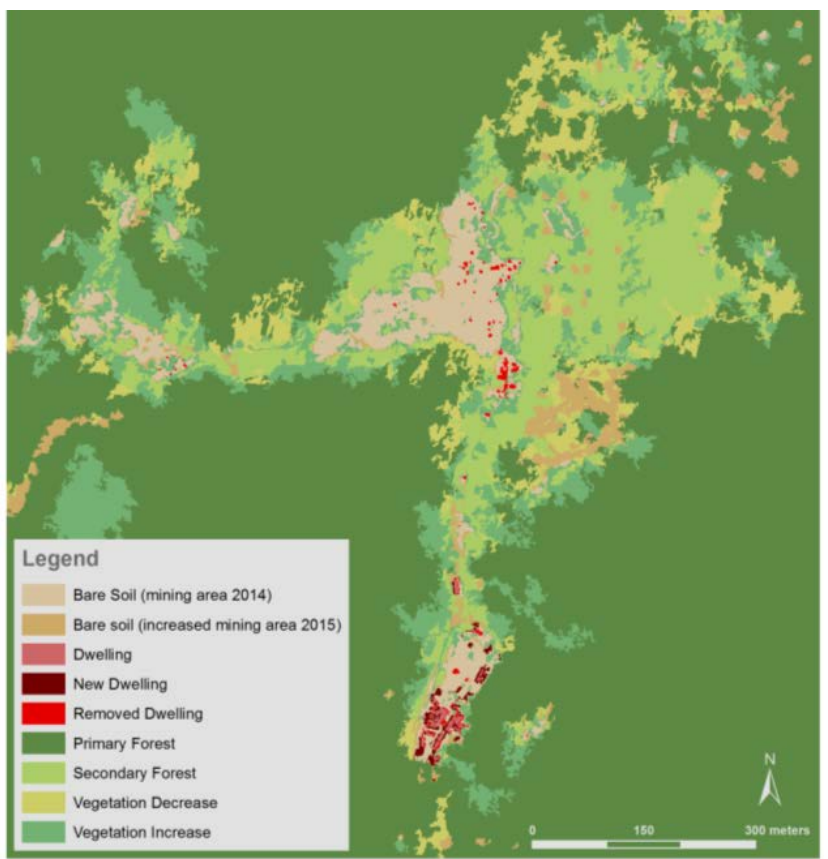

Fig. 6. Results of the land cover change from June 2014 and March 2015.

The overall accuracy of the land cover classification results are well substantiated with 87 to $92.8 \%$ (Tab. 2).

The classes primary forest and dwellings reached the best accuracies while highest errors occur for the class secondary forest. Except from the year 2015 (81.7\%) bare soil is very well classified.
Table 2. Accuracy assessment of land cover classification.

\begin{tabular}{|c|c|c|c|c|}
\hline April 2010 & $\begin{array}{c}\text { User's } \\
\text { Accuracy }\end{array}$ & $\begin{array}{l}\text { Producer's } \\
\text { Accuracy }\end{array}$ & $\begin{array}{c}\text { Overall } \\
\text { Accuracy } \\
90.53\end{array}$ & $\begin{array}{c}\text { Kappa } \\
0.88\end{array}$ \\
\hline Primary Forest & 92.45 & 87.50 & & \\
\hline Secondary Forest & 84.78 & 78.00 & & \\
\hline Dwelling & 95.24 & 95.24 & & \\
\hline Bare Soil & 82.14 & 95.83 & & \\
\hline September 2010 & & & 92.80 & 0.91 \\
\hline Primary Forest & 98.00 & 89.09 & & \\
\hline Secondary Forest & 86.27 & 84.62 & & \\
\hline Dwelling & 97.96 & 94.12 & & \\
\hline Bare Soil & 82.00 & 97.62 & & \\
\hline March 2011 & & & 88.50 & 0.85 \\
\hline Primary Forest & 96.00 & 85.71 & & \\
\hline Secondary Forest & 84.62 & 81.48 & & \\
\hline Dwelling & 94.74 & 92.31 & & \\
\hline Bare Soil & 81.67 & 96.08 & & \\
\hline June 2014 & & & 90.00 & 0.87 \\
\hline Primary Forest & 87.27 & 92.31 & & \\
\hline Secondary Forest & 93.33 & 82.35 & & \\
\hline Dwelling & 100.00 & 85.11 & & \\
\hline Bare Soil & 83.33 & 100.00 & & \\
\hline March 2015 & & & 87.00 & 0.83 \\
\hline Primary Forest & 90.20 & 97.87 & & \\
\hline Secondary Forest & 91.67 & 74.58 & & \\
\hline Dwelling & 81.82 & 97.30 & & \\
\hline Bare Soil & 84.21 & 84.21 & & \\
\hline
\end{tabular}

\section{DISCUSSION AND CONCLUSIONS}

The presented study demonstrates that OBCD provides a couple of advantages with respect to the monitoring of small-scale mining activities in a conflict region. Technically the approach is able to utilize the full spectral and spatial resolution of the VHR satellite data as required for the detection of small-scale changes. In addition, the underlying object-oriented data model builds up both horizontal as well as vertical topology and thus relations of objects and their class assignments at different hierarchical scales. The approach provides sound information about land cover changes in remote conflict areas. Detected changes detected can be linked to on-site activities reflecting the political situation responsible for certain trends in mineral extraction. The expansion of bare soil areas is related to selective activities of a fraction amount of formerly present workers. In 2009 Bisie has been visited by the International Peace Information Service (IPIS). At that time about 2,000 people were working at the mining site (IPIS/OECD 2015). During the five month monitoring period in 2010 mining was on a high and even still increasing level with about 3,000 miners working in Bisie. Following the statistics they were extracting a daily average of about 1,526 kg Cassiterite (Zingg Wimmer and Hilgert 2011). In autumn 2010 President Kabila announced a mining ban in order to stop the well-established military involvement and the link between mineral resources and DRC's conflict. 
Since September 2010 the number of workers in Bisie dramatically decreased to a few hundred at the end of a mining ban (IPIS/OECD 2015). The satellite analysis shows an impressive decrease of dwellings during this half year and formerly non-vegetated areas became overgrown. The ban, which has been released in March 2011, resulted in a significant decline of mineral extraction.

Still, it has to be noted that mining did not completely stop (Sells 2013; Zingg Wimmer and Hilgert 2011) which can also be concluded due to the observed further increase of the mining area in certain parts of the mining site. The development of the southern area of the mining site is very interesting since the establishment of larger buildings for accommodation, offices, fuel storages, showers as well as ablution facilities and a helicopter landing pad suggest a professional exploitation having been established in 2014 and 2015. Indeed, Alphamin Resources Corporation, started the industrial exploration of cassiterite at Bisie in 2014 (Witley and Leighton 2015).

The use of Earth observation data has great potential for the monitoring of mining activities. Especially in conflict torn, remote areas, the provision of independent, area-wide and upto-date information on mining activities is of high importance. Complemented by socio-economic and political information more detailed assessments of the situation in conflict regions become possible (Zingg Wimmer and Hilgert 2011). The proposed multi-dimensional monitoring of mineral exploitation and its dynamics may contribute to a characterization of affected areas as suggested by UNEP (2009) and finally may support the development of recommendations for conflict mitigation and peace building.

\section{ACKNOWLEDGEMENTS}

This study was partially supported by the European Union's $7^{\text {th }}$ Framework Programme project G-MOSAIC (Contract No. 218822). The authors are grateful to Prof. Dr. Stefan Dech (DLR-DFD) and European Space Imaging (EUSI) for the provision of the WorldView data used within this study. The software eCognition was kindly provided by Trimble Munich.

\section{REFERENCES}

Benz, U. C., Hofmann, P., Willhauck, G., Lingenfelder, I. and Heynen, M., 2004: Multi-resolution, object-oriented fuzzy analysis of remote sensing data for GIS-ready information. ISPRS Journal of photogrammetry and remote sensing, 58(3), 239-258.

Blaschke, T., 2010: Object based image analysis for remote sensing. ISPRS journal of photogrammetry and remote sensing, 65(1), 2-16.

Blaschke, T., 2005: Towards a framework for change detection based on image objects. Göttinger Geographische Abhandlungen, 113, 1-9.

Burnley, C., 2011: Natural Resources Conflict in the Democratic Republic of the Congo: A Question of Governance?. Sustainable Development Law \& Policy 12, no. 1 (2011): 7-11, 52-53.

Christopher, P., Deskevich, M. P., 2014: Hyperspherical pan sharpening. U.S. Patent No. 8,737,733. 27 May 2014.

Definiens, 2009: What's new eCognition Developer 8? Working with maps. New OBIA dimensions. Definiens AG, Munich.
Frerks, G., Dietz, T. and van der Zaag, P., 2014: Conflict and cooperation on natural resources: Justifying the CoCooN programme. In: Conflicts over Natural Resources in the Global South - Conceptual Approaches.

Global Witness, 2009: Faced with a gun, what can you do?: War and the militarisation of mining in eastern Congo. Global Witness

Ghosh, A. and Joshi, P.K., 2013: Assessment of pan-sharpened very high-resolution WorldView-2 images. International Journal of Remote Sensing, Vol. 34, Iss. 23, 2013.

Hussain M., Chen, D., Cheng, A., Wei, H. and Stanley. D., 2013: Change detection from remotely sensed images: from pixel-based to object-based approaches. ISPRS J Photogramm Remote Sens. 80: 91-106.

Lang, S. and Blaschke, T., 2003: Hierarchical object representation -Comparative multi-scale mapping of anthropogenic and natural features. International Archives of Photogrammetry, Remote Sensing and Spatial Information Sciences, Vol. No. XXXIV-3/W8, 181-186.

Le Billon, P., 2010: The political ecology of war: natural resources and armed conflicts, Political Geography 20 (5), 561584.

Le Billon, P., 2005: Fuelling War: Natural Resources and Armed Conflicts; Number 373; Routledge: London, UK.

Melvin, N. and de Koning, R., 2011: Resources and armed conflict. In: SIPRI Yearbook 2011, Armaments, Disarmament and International Security. Stockholm International Peace Research Institute.

Mildner, S.A., Lauster, G., and Wodni, W., 2011: Scarcity and abundance revisited: A literature review on natural resources and conflict. Int. J. Confl. Violence 2011, 5, 155-172.

Schöpfer, E., Lang, S, and Strobl, J., 2010: Segmentation and Object-Based Image Analysis. In: Rashed, Tarek, Jürgens, Carsten (Eds.), Remote Sensing of Urban and Suburban Areas, Volume 10 of the series Remote Sensing and Digital Image Processing, 181-192.

Schoepfer, E. and Kranz, O., 2010: Monitoring natural resources in conflict using an object-based multiscale image analysis approach, GEOBIA 2010, Ghent, Belgium, 2010; In: Addink, E.A.; Van Coillie, F.M.B., Eds. International Society for Photogrametry and Remote Sensing (ISPRS): Ghent, Belgium.

Tiede, D., 2014: A new geospatial overlay method for the analysis and visualization of spatial change patterns using object-oriented data modeling concepts, Cartography and Geographic Information Science, 41:3, 227-234, DOI: 10.1080/15230406.2014.901900

Tu, T. M., Hsu, C. L., Tu, P. Y. and Lee, C. H., 2012: An Adjustable Pan-Sharpening Approach for IKONOS/ QuickBird/GeoEye-1/WorldView-2 Imagery. IEEE Journal of Selected Topics in Applied Earth Observations and Remote Sensing, vol. 5, no. 1, pp. 125-134.

UNEP, 2009: From Conflict to Peacebuilding. The Role of Natural Resources and the Environment.

Witley, J.C. and Leighton, R.G., 2015: Bisie Tin Project. NI 43101 Technical Report - 15 October 2015 Mineral Resource Estimate. Prepared By The MSA Group (Pty) Ltd for: Alphamin Resources Corporation. Johannesburg, South Africa. 
Witley, J.C. and Leighton, R.G., Pooley, A.D., 2016: Bisie Tin Project. NI 43-101 Technical Report - 19 February 2016 Feasibility Study Report. Prepared for: Alphamin Resources Corporation. Johannesburg, South Africa.

Zingg Wimmer, S. and Hilgert, F., 2011: Bisie. A one-year snapshot of the DRC's principal cassiterite mine. International Peace Information Service.

Zhang, Y. and Mishra, R.K., 2014: From UNB PanSharp to Fuze Go - the success behind the pan-sharpening algorithm. International Journal of Image and Data Fusion,Vol. 5, Iss. 1, 2014. 